\title{
Lope más allá del teatro: La Dorotea
}

Lope beyond the Theater: La Dorotea

\section{Florencia Calvo}

Instituto de Filología y Literaturas Hispánicas "Dr. Amado Alonso"

Universidad de Buenos Aires- CONICET, Argentina

Los trabajos aquí reunidos están todos dedicados al análisis de diversos aspectos de La Dorotea de Lope de Vega, una de las obras más complejas de la producción no dramática del autor barroco. La Dorotea, publicada en 1632 en los últimos años de vida de su autor, siempre se ha entendido como una obra original y emblemática debido a diversos factores que han ido variando a la par de su situación dentro del canon. Así, los ejes de lectura y de análisis posibles son múltiples y han ido definiendo también su trayectoria crítica. Los acercamientos al texto son múltiples y tradicionalmente se han centrado en la reelaboración de la materia autobiográfica, en sus matrices formales y en la construcción de sus personajes que la acercaban a la Celestina y a la descendencia celestinesca, a la mezcla de prosa y poesía dentro del texto, a las polémicas literarias con los nuevos poetas o su inserción dentro de lo que se ha denominado la senectute de su autor.

En épocas más recientes se ha tratado de pensar cómo La Dorotea se conforma en un espesor en el que se pueden ir delimitando elementos que recorren toda la obra de Lope, no solamente en lo obvio, lo que tiene que ver con lo argumental; sino además en lo que tiene que ver con la configuración de una figura de autor, de poeta y por qué no de dramaturgo. Desde el enamorado al erudito, desde el poeta al preceptista o desde el dramaturgo a la máscara autoparódica podemos encontrarlos en la obra y podemos además verificar cómo todas esas instancias no son creación de esta última época sino que estos años funcionan como espacio en el que estas figuras, ya diseminadas a lo largo de los años anteriores, encuentran su consecución final. $L a$ Dorotea es así, en tanto obra tardía de Lope de Vega, el lugar de la confluencia de la mayoría de los vectores que conforman la totalidad de la producción lopesca. Al referirme a vectores constitutivos se piensa en una suma de elementos de análisis que no se reducen a componentes temáticos de la obra sino que permiten explorarla en distintos niveles de interpretación. De este modo se han ido sumando elementos al abordaje primero del texto: delimitar los mecanismos mediante los que Lope de Vega ha ficcionalizado su vida en su obra, los sentidos de la inclusión de referencias a las polémicas acerca de la Comedia nueva y los géneros dramáticos, la peculiaridad del género elegido para relatar una vez más sus amores con Elena Osorio, su filiación con la literatura celestinesca o la reescritura de sus propias composiciones poéticas.

En esta compilación que presentamos cada uno de los trabajos ha intentado ir un paso más allá de estas vertientes críticas y propone acercamientos novedosos sobre un texto cuyas potencialidades están lejos de ser agotadas. Cada una de estas lecturas aporta su especificidad y se remite a distintos aspectos de La Dorotea.

Un grupo de ellas reflexiona sobre cuestiones de narrativa; así mientras Carlos Brito Díaz recorre gran parte de la narrativa de Lope a partir de la noción de escrilector y su relación con la escritura cervantina desde dicha categoría; Patricia Festini demuestra cómo en el "Prólogo al Teatro" ya se problematiza la dicotomía historia/ poesía que no sólo informará el texto sino que además va a acercar la poética de La Dorotea a la de la novela corta. Ximena González, por su parte, se detiene en la poesía del texto y mediante su análisis añade sentido al conjunto de barquillas al trabajar el corpus compuesto por los idilios piscatorios desde el examen de sus recurrencias, continuidades e isotopías y añade nuevos sentidos a la alternancia de prosas y versos como parte de la conformación estructural de la obra más allá de la polémica si fueron o no escritas para el fallecimiento de Marta de Nevares. Dos trabajos se detienen en la relación del texto con el género dramático: Silvia López D’Amato repasa las funciones dramáticas del personaje de Laurencio y Matías Spector desprende sentidos 
más amplios relacionados con la predestinación y el libre albedrío a partir de las relaciones entre el Coro y la Acción. Por último dos trabajos exploran las hibridaciones y las deudas con otros géneros, Gloria Chicote se detiene en la relación entre el texto y la Celestina, desviando el foco de los análisis canónicos y centrando la comparación en cuestiones referidas al estilo y Florencia Calvo intenta definir cómo la obra recibe distintas variables identificadas con lo elegíaco no tan to como una marca biográfica sino como un espacio que relativiza los límites genéricos.

La amplitud de posibilidades verificada a lo largo de la historiografía crítica de La Dorotea y ofrecida por la propia obra es la que podrá apreciarse también en este conjunto que aquí presentamos. Más allá de las diferencias de cada uno de los autores queda claro que es el propio texto el que habilita esta gran cantidad de abordajes: el objeto en tanto variedad absoluta opera sobre sus potenciales lecturas y las diversifica tal como lo podremos comprobar en las páginas que siguen. 